\title{
It's my choice! Investigating barriers to pro-social blood donating behaviour
}

\begin{abstract}
Purpose - Barriers to pro-social behaviour in the context of blood donation using selfdetermination theory was investigated.

Design/ methodology/ approach - Respondents were recruited through intercepts at one major university and at points within the community in a capital city in Australia. Sampling was conducted over a three week period resulting in a sample of 617 respondents.
\end{abstract}

Findings - Results show intrinsic motivations positively influence intentions toward blood donation, self-identity and locus of control. Further, despite positively influencing other factors, external regulation positively influenced amotivation indicating the more likely people feel pressured to donate blood, the less likely they will be motivated to donate blood.

Originality/ value - Simultaneous consideration of amotivation with bblood donation intentions permits a broader understanding of blood donation to be obtained.

Keywords Pro-social behaviour, Blood donation, Self-Determination theory, Australia Paper type Research paper 


\section{Introduction}

In Australia only 1 in 30 people give blood while 1 in 3 people will need blood in their lifetime (Australian Red Cross, 2014). In the US, despite 38\% of the population being eligible to donate blood, less than 10\% actually donate each year (Red Cross, 2014). The increased demand for blood donation coupled with the shortage of blood donors remains a critical issue (Australian Red Cross Blood Services, 2007; Fergusson et al., 2008). One of the key deciding factors in blood donation is motivation (Kersraian and Maghsudlu, 2012; Zito et al., 2012). Hence, understanding motivations to engage in and adhere to this prosocial behaviour is of vital importance for the maintenance and improvement of a nation's health. Motivation has been central and recurrent in the field of psychology (Ryan and Deci, 2000). Concerning energy, direction, persistence and mobilisation, what is important from this psychological research is that in the real world, the value of understanding motivation lies in its outcomes: motivation produces; that is, theories of motivation assume that people participate in behaviours they believe will lead to desired outcomes or goals (Deci and Ryan, 2000). Satisfaction contiguous with these goals is founded upon the social context surrounding the goal (extrinsic motivation) and individual personality factors (intrinsic motivation) (Mowen, 2000), or even a general non-intention to act (amotivation) (Vallerand and Bissonnette, 1992). Situations favouring these motivations facilitate accepted growth processes, whereas those that prevent self-sufficiency, proficiency, or affiliation are associated with poorer performance and well-being (Deci and Ryan, 2000) and may lead to insecurities (Burroughs et. al, 2013).

While motivation has received considerable attention (Moore, 1991; Stelle et al.,2008) research attention has not been directed towards amotivation. This study will investigate the impact of amotivation (i.e. a "state of lacking an intention to act"; Ryan and Deci 2000, p. 61) and locus of control (Rotter, 1966), examining their interplay between SDT 
and intentions, a point not previously researched in pro-social behaviour. This study will provide further insights into barriers towards the pro-social behaviour of blood donation. So far, little research has tried to discriminate between these many factors surrounding pro-social decision making. First, this paper aimed to determine whether Self-Determination Theory's (SDT) offered any explanatory potential to explain consumer motivation to donate blood.

Second, this paper sought to extend beyond intentions to simultaneously consider amotivation ensuring that a more considered treatment of factors was undertaken. Broader consideration is important given factors simultaneously motivating some while having the opposite effect on others should not be emphasised in strategic planning efforts. Finally, this study empirically examines the interaction between locus of self-control and amotivation within SDT and intentions, a point not previously researched in pro-social behaviour.

\section{Literature Review.}

Whilst early researchers may have cast doubt on motivational research (see Jameson, 1971), current consumer behavioural research on motivations in marketing has varied from goal commitment, progress and motivation (Zhang and Huang, 2010), to cultural values and brand extensions (Ng, 2010) to product variety (Etkin and Ratkin, 2012), to user generated video content (Poch and Martin, 2014). Missing from this current marketing research are motivations behind pro-social behaviour (Burroughs et. al., 2013).

\section{Pro-social behaviour}

Pro-social behaviour, defined as voluntary behaviour intended to benefit others (e.g. blood donation, volunteering activities) (Eisenberg et. al., 2006), involves making decisions in regards to others based on comparisons of outcomes for self (Guroglu et al., 2014). In this study, we categorize blood donation as a behaviour that people undertake voluntarily with 
few obvious or immediate rewards (Masser et al., 2008). Pro-social behaviour is based upon the interests the individual serves: one's own or others' (Schwartz, 2006).

There is a need for research to be conducted within a theoretical framework that considers a range of individual factors motivating pro-social behaviour especially blood donation (Smith and McSweeney, 2007). Blood donation has been considered as "perhaps the purest example of altruistic or pro-social behaviour (Titmuss, 1971, p. 46). One theory that provides a framework for assessing the psychological processes underlying motivations and behaviour is that of Self-Determination Theory (Deci and Ryan, 1980, 1985, 1991).

\section{Self-Determination Theory}

The universal needs that motivate human desires and behaviours (i.e., the seminal needs from which all others stem) has long been a major focus of psychological research (Burroughs et. al., 2013). Over the years three primary theories attest to measurement of such needs: Maslow's needs hierarchy (Maslow, 1970), acquired needs theory (McClelland, 1987), and self-determination theory (Deci and Ryan 1985; Ryan and Deci 2000). Of these theories selfdetermination theory (SDT) may be considered a macro theory of human motivation (Deci and Ryan, 2008). SDT concerns the degree to which individuals are able to fulfil their basic psychological needs when in pursuit of their valued outcomes (Deci and Ryan, 2008).

Based on the three fundamental psychological needs of autonomy (e.g. physical and economic security), competence (e.g. a meaningful and valuable life), and relatedness (e.g. social needs) (Burroughs et. al., 20013; Ng et. al., 2012), the most central distinction in SDT is between autonomous motivation and controlled motivation (Deci and Ryan, 2008). Autonomous motivation encompasses both intrinsic motivation and extrinsic motivation of the type where the value of the activity identified ideally becomes a part of a persons' sense of self (Deci and Ryan, 2008). Such autonomous motivation creates a self-endorsement of 
their actions; for example, a sense of fulfilment and lasting positive emotions (Andreoni 1990; Burroughs et. al., 2013). As the overall perspective of autonomous motivation in SDT is the individual's own ability and willingness to make the decision, autonomous motivation is referred to as intrinsic motivation.

In contrast, controlled motivations consist of both external regulation, in which one's behaviour is a function of external contingencies of reward or punishment, and selfregulation, wherein the external regulation of action has been partially internalized and is energized by factors such as an approval motive, avoidance of shame, contingent self-esteem, and ego-involvements (Deci and Ryan, 2008). When people are controlled, they experience pressure to think, feel, or behave in particular ways. From an overall perspective controlled motivation in SDT is different from autonomous motivation in that the individual's behaviour is not based upon their own willingness and ability but external sources and the negative consequences of not adhering to those demands. Thus, controlled motivation is referred to as extrinsic motivation.

\section{Intrinsic Motivation}

Intrinsically motivated behaviours are produced and maintained because the enjoyment of such activities reinforces the behaviour (Lavigne et. al., 2009). In the context of blood donation, altruistic reason has been identified as a key reason for donating blood (Glyn et. al., 2002; Lemmens et. al., 2009; Misje et. al., 2005). Such motivation describes the inherent tendency of the individual to pursue interesting and challenging tasks in an effort to foster growth (Deci and Ryan, 1985). However literature has made a distinction between two types of intrinsic motivation: pure altruism and warm glow (Andreoni 1989, 1990). While people motivated by pure altruism (Andreoni, 1989) take a holistic view to giving (they care about the total public good), people motivated by warm glow (Andreoni, 1990) care about their 
own individual donation, properties associated with a private good (Tonin and Vlassopoulos, 2014). Even though pure altruistic motivations may take a holistic perspective, current research argues that warm glow incorporates such motivations and extends to areas of selfimage, social image, and esteem (see: Benabou and Tirole, 2006; Ellingsen and Johannesson 2008, 2011; Andreoni and Bernheim 2009; Grossman 2010; Tonin and Vlassopoulos, 2014), factors associated with self-determination theory (Deci and Ryan. 1985, 1991, 2000, 2008). Thus, for this paper intrinsic motivation corresponds to warm glow motivations.

The relationship between intrinsic motivation and positive outcomes has been supported in previous research (Cerasoli and Ford, 2014). Prior research identified intrinsically motivated students had higher levels of task persistence and greater desire toward educational behaviour's (e.g. attending class and staying in school) (Hardre and Reeve, 2003; Robbins et. al., 2004). The implication from such motivations being students tending towards higher levels of confidence and persistence, leading to deeper level learning behaviour's and reflected in better exam marks (Simons et al., 2004). Conducting a 40 year meta-analysis of intrinsic motivations on behaviour, Cerasoli et. al., (in press) support positive relationships between intrinsic motivation and behaviour. This leads to the following hypothesis:

H1: Intrinsic motivation toward blood donation will have a positive influence on blood donation intentions

SDT suggests every activity is carried out for its own worth providing positive emotions and feelings of self-worth (Deci and Ryan, 2000). The value associated with these activities thus becomes a part of a persons' sense of self (Deci and Ryan, 2008), with the categorisation and internalisation of these emotions and self-worth becoming an integral part of a person's identity (Vallerand et al., 2003). A person's meanings and expectations 
associated with the categorization into the self then forms a set of identity standards guiding identity and its associated behaviours (Rise et al., 2010; Stets and Burke, 2000). This leads to the following hypotheses:

H2: Intrinsic motivations toward blood donation will have a positive influence on identity.

Behaviours' are produced and maintained because the enjoyment of such tasks impart reinforces the behaviour (Kindelberger and Tsao, 2014; Lavigne et. al., 2009) indicating some control over the behaviour. This intrinsically motivated control can be perceived in two ways: where the action was their own but not entirely under their control (e.g. defined by the situation surrounding the decision) referred to as external control. If the person perceives that the event is contingent upon his own behaviour or his own relatively permanent characteristics (e.g. pro-social behaviour), this is internal control (Rotter, 1966). Previous research has found individuals who feel more in control of their own outcomes are more likely to be more optimistic, and engage in positive health behaviour's (Ryon and Gleason, 2014; Griffin and O’Cass 2010). Importantly, intrinsic motivation will influence locus of control, leading to the following hypothesis:

H3: Intrinsic motivation toward blood donation will have a positive influence on locus of control.

\section{Extrinsic Motivation}

Self-determination theory states that extrinsic motivation is not invariably controlling but can vary in the degree to which it is self-determined versus controlled therefore becoming internalised (Deci and Ryan, 2000). This internalisation is a process in which individuals transform socially sanctioned requests into personally endorsed values and self-regulations (Ryan et al., 1985). These values and self-regulations provide the individual's sense of self, 
and become accepted by them as their own. In doing so, they will become more integrated psychologically and socially. Whilst not all external motivations become fully internalised and integrated Deci and Ryan (1985). . Therefore, we expect extrinsic motivations would positively influence intrinsic motivations leading to the following hypothesis:

H4: Extrinsic motivations toward blood donation will have a positive influence on intrinsic motivations toward blood donation.

Every activity is carried out for its own worth to provide positive emotions and feelings of self-worth according to both external and internal motivations (Deci and Ryan, 2000). If the internalisation of external socially sanctioned requests become a part of an individual's personally endorsed values and self-regulations (Ryan et al., 1985), then, like intrinsic motivations, the value associated with these activities thus becomes a part of a persons' sense of self (Deci and Ryan, 2008), and an integral part of a person's identity (Vallerand et al., 2003). Again, like intrinsic motivation, the values associated with the internalisation of the extrinsic motivations then helps form a set of identity standards and associated behaviours (Rise et al., 2010; Stets and Burke, 2000).This leads to the following hypotheses:

H5: Extrinsic motivations toward blood donation will have a positive influence on identity.

Even though not all extrinsic motivations become fully internalised and integrated the dominant feature of these motivations is that as they become more internalised they increase desire and determination (Ryan et. al., 1997), thus the greater the internalisation of extrinsic motivation the greater the control exerted over the behaviour. Therefore as extrinsic motivation increases so does behaviour. This leads to the following hypothesis: 
H6: Extrinsic motivations toward blood donation will have a positive influence on blood donation intentions.

\section{Amotivation.}

Deci and Ryan (1985) also claim that a third construct, amotivation, must be considered to fully understand human behaviour (Vallerand and Bissonnette, 1992). Amotivation has been described as the state of lacking the intention to act ( $\mathrm{Ng}$ et. al., 2012). Amotivation can result from either, or combination of, three reasons; not valuing an activity (Ryan, 1995), not feeling competent to do it (Bandura, 1986), or not expecting it to yield the desired outcome (Seligman, 1975). A construct largely researched with respect to academic activities (see Ratelle et al. 2007; Vallerand and Bissonnette 1992), the construct generally appears to be related to negative or unfavourable outcomes (Jung, 2013). This in direct contrast to intrinsic motivation which is based on the inherent enjoyment derived from the behaviour itself, behaviours congruent with personal goals and values that reflect the personal value outcomes (Ng et. al., 2012). This leads to the following hypothesis:

H7: Intrinsic motivation toward blood donation will have a negative influence on amotivation toward blood donation.

While extrinsic motivations become internalised and self-regulatory they are not intrinsic motivations (Deci and Ryan, 2000). These motivations reflect internal pressures such as contingent self-worth, guilt, shame, and feelings of approval and compliance with external pressures or rewards (Ng et. al., 2012), rather than the joy of the behaviour. As such, these internalised pressures provide motivation to thwart any perceived consequences of performing the behaviour. Greater extrinsic factors influencing motivations can thus inhibit a person's willingness to act, leading to the following hypothesis. 
H8: Extrinsic motivation toward blood donation will have a positive influence on amotivation toward blood donation.

As stated, amotivation refers to the state of lacking any intention to act ( $\mathrm{Ng}$ et. al., 2012) and is a completely non-self-determined form of regulation (Markland and Tobin, 2004). In contrast to intrinsic and extrinsic motivation, amotivation represents the lack of motivation and thus a complete lack of self-determination with respect to the target behaviour (Deci and Ryan, 2000). If both intrinsic and extrinsic motivation have a positive influence on behaviour and amotivation stands in contrast to these forms of motivation then this leads to the following hypotheses:

H9: Amotivation toward blood donation will have a negative influence on blood donation intentions

Amotivated behaviours have neither intrinsically nor extrinsically rewards associated with the behaviour and thus become non-motivated behaviours (Vallerand and Bissonnette, 1992). Such behaviours are the least self-determined because of this lack of sense of purpose and with no expectation of reward or the possibility of changing the behaviour can be perceived as similar to learned helplessness (Abramson et al., 1978). The psychological ramifications of amotivation being that the individual will experience feelings of incompetence and expectancies of uncontrollability (Vallerand and Bissonnette, 1992). This is in contrast to self-identity which refers to salient and enduring aspects of one's selfperception (Rise et al., 2010; Thoits, 1992, 2013) as people apply socially meaningful categories to define themselves (Thoits and Virshup, 1997). Thus, self-identities are the perspective one takes toward oneself implying that one incorporates the meanings and expectations associated with a relevant categorization into the self, thereby forming a set of 
standards that guide identity-relevant behaviours (Stets and Burke, 2000). As the core of an identity is the incorporation, into the self, of the meanings and expectations associated with a defined role and behavioural expectation associated with that role (Stets and Burke, 2000) this would suggest amotivation would decrease as one's sense of self identity becomes stronger leading to the following hypothesis:

H10: Self-identity will have a negative influence on amotivation toward blood donation

Amotivation is likely to be affected by an individual's degree of self-control. Intrinsic motives energize, select, and direct behaviour towards motive congruent goal states (Deci and Ryan, 2000; McClelland, 1985). Where that behaviour (e.g. pro-social behaviour) is contingent upon the individuals own characteristics then that behaviour is determined more by internal control than external control (Rotter, 1966), especially where that motive has high affective and/or normative commitment (Chen and Wang, 2007), thus the greater the level of internal control the less the level of amotivation. This leads to the following hypothesis:

H11: Locus of control will have a negative influence on amotivation

\section{Methodology}

\section{Data collection}

Using a team of trained research assistants and a self-administered survey, respondents were recruited conveniently through intercepts at a major public university (one of the top 3 universities in the state) and various points within the community in a capital city in Australia. Locations were chosen to maximise respondent heterogeneity. Sampling was conducted over a three week period resulting in an initial sample of 636 respondents. This was reduced to 617 after removal of missing data. Allowing for rounding errors, the final sampling ratio showed $49 \%$ of the sample to be males and $51 \%$ females. Average age of the 
respondents was $35(\mathrm{SD}=14)$ with $57 \%$ being non-students. This sample was deemed appropriate for the research.

\section{Survey Instrument}

The survey asked questions related to blood donation: "Please indicate your agreement with each of the following statements about donating blood". The 5 item Locus of control construct was adapted from Rotters (1966). Work Locus of Control Scale as tested by Spector (1988) and measured the general locus of control items rather than the specific work locus of control items. Each item was measured using a 6-point Likert scale anchored with 1 (strongly disagree) and 6 (strongly agree) with 2 items reverse coded to reduce common method variance (CMV) (see Lindell and Whitney, 2001). Reverse coded trust items were "A good life is primarily a matter of good fortune" and "Getting the life you desire is mostly a matter of luck". High scores on this scale represent greater internal locus of control.

All other constructs were measured using Guay et al's, (2000) Situational Motivation Scale (SIMS). Designed to assess intrinsic motivation, self-identity regulation, external regulation, and amotivation (Deci and Ryan, 1985, 1991) in field and laboratory settings this scale was developed using five studies to validate the SIMS. Their results show the SIMS to be composed of the 4 constructs advocated by Deci and Ryan $(1985,1991)$ identified above. Again a 6 point scale was used anchored with 1 (strongly disagree) and 6 (strongly agree). High scores on these scales represent high levels of intrinsic motivation, self-identity regulation, external regulation, and amotivation.

Intentions were measured using a 6-point Likert scale consisting of 3 items anchored with 1 (strongly disagree) and 6 (strongly agree) that was adapted from Ajzen and Fishbein (1980). For a complete list of the questions used refer to Appendix 1. 
After recoding the reverse coded items, reliability analysis was conducted. Initial analysis showed some constructs to be below the suggested .7 threshold (Nunally, 1978; Nunnally and Bernstein, 1994). Items were individually removed based upon their "Alpha if item deleted" figure; that is, should the alpha increase with the deletion of that item then the item was removed and the analysis run again until the desired .7 level was achieved (for a list of all the items including those removed refer to Table 1). While Locus of control shows an alpha of only .69 this was considered sufficient for this study.

$<<$ INSERT TABLE 1 HERE $>>$

\section{Analysis Method}

Structural equation modelling (SEM) was applied

Specifically, the two-step procedure advocated by Anderson and Gerbing (1988) using Amos 20 software was employed. A measurement model was first developed using confirmatory factor analysis (CFA) to test the validity of the individual measurement items after which a full structural model was run to examine the relationships between the variables of interest.

Model fit is a major consideration in SEM (Yuan, 2005). Two critical criteria determined the fit indices chosen: the sample size (Bollen, 1990) and the degrees of freedom (df) (Kenny, 2014). Chi square ( $\chi 2)$, along with Root Mean Square Error of Approximation (RMSEA) (values between .06 and .08 are considered a good fit and values between .08 and .10 a fair fit: see MacCallum et al., 1996) were used as the traditional measures of absolute fit (Hooper et al., 2008; Hu and Bentler, 1999). As all items were measured with the same size scale, requiring no standardization of scales (see Hooper, et. al., 2008; Kline, 2005), Root Mean Square Residual (RMR), was also used as an absolute measure of fit with values between .08 and .05 deemed acceptable (Bryne, 1998; Diamantopoulos and Siguaw, 2000; Hooper et al., 2008; Hu and Bentler, 1999). 
However absolute fit indices (Hooper et. al., 2008; Kenny, 2014) are affected by sample size and calculated using degrees of freedom causing potential lack of statistical power (Bollen, 1990; Kenny and McCoach, 2003). To overcome this, comparative fit index (CFI) was used chosen for its lower susceptibility to sample size (Fan et al., 1999), with CFI indices > .95 indicative of good fit (Hu and Bentler, 1999).

\section{Measurement model.}

The initial measurement model was run using the items defined by the reliability tests (refer to Table 1). Convergent and discriminant validity tests were next run to assess the validity of the individual items on the latent constructs and potential model modification. Model modification was undertaken using 4 as the criterion value for change (i.e. a change in respecification of the model will result in a 1 degree change in $\chi^{2}$ ) (Barrett, 2007). This criterion resulted in the removal of three of Locus of control item, one Intrinsic motivation item ("feel good when doing the activity"), and one self-identity ("my personal decision"). The resultant model showed reasonable fit: $\chi^{2}=198.200(\mathrm{df}=117), p=.000, \mathrm{RMSEA}=0.034$ $(\mathrm{LO} 90=.035 ; \mathrm{HI} 90=.041), \mathrm{CFI}=.98 ; \mathrm{RMR}=.065$

Average variance extracted (AVE) was used to assess both convergent and discriminant validity. Using factor loadings Fornell and Larker (1981) suggest constructs should contain more than $50 \%$ explained or common variance in the factor analytic sense $(A V E>.5)$; that is, less than 50\% error variance (Dillon and Goldstein 1984). As items were removed from the initial reliability analysis, reliability checks (Joreskog rho) were again conducted as a measure of convergent validity based upon the concepts proposed by Werts et. al., (1974) and Bagozzi (1980) (see Fornell and Larker, 1981). Table 1 shows all constructs to have good convergent validity (AVE's > .50; Joreskog rho $>.7)$. 
Discriminant validity checks were assessed using the squared correlations against the Average Variance Extracted (AVE) of each dimension following Fornell and Larker's (1981) criteria. For discriminant validity to be present, the AVE had to surpass the squared correlation present between the construct and the other dimensions. Adherence to the above criteria illustrates that each construct measures a distinct component of a variable that the others don't (Hair et al., 2010) providing statistical support that respondents could differentiate between each of the individual constructs. Discriminant validity was supported for all constructs in this study though not displayed for the sake of parsimony.

\section{Results}

The full path model was used to determine the estimated path coefficients $(\beta)$ and associated t-values, with t-values exceeding $1.96(\mathrm{p}<.05)$ for path estimates deemed statistically significant. The estimated structural model was acceptable $(\chi 2=224.669$ [df $=122], p=.000$, RMSEA $=0.037[\mathrm{LO} 90=.029 ; \mathrm{HI} 90=.044], \mathrm{CFI}=.98 ; \mathrm{RMR}=.073$.) with Table 2 showing standardised path estimates to be significant for all hypotheses. Results show intrinsic motivations positively influenced intentions $(\beta=.101 ; \mathrm{p}=.025)$, self-identity $(\beta=$ $.567 ; p=.000)$ and locus of control $(\beta=.100 ; p=.048)$; hypotheses 1,2 , and 3 were supported. Extrinsic motivations were found to have a positive influence on intrinsic motivation $(\beta=.249 ; \mathrm{p}=.000)$, identity $(\beta=.247 ; \mathrm{p}=.000)$ and intentions $(\beta=.169 ; \mathrm{p}=$ .000 ), supporting hypotheses 4,5 , and 6 . A negative relationship was found between intrinsic motivation and amotivation $(\beta=-.214 ; \mathrm{p}=.000)$ supporting hypothesis 7 with the relationship being reversed between extrinsic motivations and amotivation $(\beta=.176 ; \mathrm{p}=$ .000) supporting hypothesis 8 . Hypothesis 9 was supported with amotivation shown to have a negative relationship with intentions $(\beta=-.265 ; \mathrm{p}=.000)$. The positive relationship between identity and amotivation $(\beta=.190 ; \mathrm{p}=.007)$ did not support hypothesis 10 , though 
hypothesis 11 was supported with locus of control having a negative influence on amotivation $(\beta=-.256 ; \mathrm{p}=.000)$.

\section{$<<$ INSERT TABLE 2 ABOUT HERE $>>$}

\section{Discussion and Managerial Implications}

The current paper contributes to the literature in three ways. First, the paper provides empirical evidence of Self-Determination Theory's (SDT) ability to explain consumer motivation delivering a viable method for advancing academic research in marketing, strategic marketing practice, and public policy. Second, this paper identified the influence of factors on both motivation and amotivation to provide a holistic view to inform strategic planning. Finally, this study contributed empirical evidence of the interaction between locus of self-control and amotivation within SDT and intentions, a point not previously researched in pro-social behaviour. Each contribution is briefly discussed in turn.

The results of this study support the use of self-determination theory as a means to assess the degree to which individuals are able to fulfil their basic psychological needs when in pursuit of their valued outcomes (Deci and Ryan, 2008). Relationships established in previous studies were supported in the current study. For example, intrinsic motivations positively influenced intention toward blood donation (e.g. Cerasoli and Ford, 2014), selfidentity and locus of control (e.g. Ryan and Gleason, 2014). We need to be mindful that behaviour is governed by inertia and habits, many of which are not explained by behavioural intentions. The dominant focus in research has been explaining and predicting behavioural intentions (see Brennan et al. 2015 who outline a broad range of theories where behavioural intention is the dependent variable).

This study provides further insights into barriers towards the pro-social behaviour of blood donation by exploring the impact of amotivation and locus of control. Subsequently, 
examining their interplay between SDT and intentions, a point not previously researched. Similar to Jung (2013) amotivation was shown to have a direct negative influence on outcomes though a means to counter this negative relationship would be to increase a donors levels of intrinsic value, as reflected in their personal value outcomes (Ng et.al., 2012). Such an increase will have a positive influence on locus of control in that they feel more in control over their donating behaviour and are more likely to engage in positive health behaviour (Ryon and Gleason, 2014). An added benefit of an increase in locus of control is also the reduction in amotivation as the individual feels more internal control than external control over their commitment to donate (Chen and Wang, 2007; Rotter, 1966). This finding supports other studies where external motivation and external incentives will have a negative motivational 'crowding-out' effect, resulting in lower levels of donation (Niza et al., 2013; Oakley and Ashton, 1997). Thus, simultaneous consideration of amotivation extends our understanding beyond the factors that can be used to motivate change towards understanding the factors driving no actions.

\section{Management implications}

Overall, the results show that intrinsic motivation and locus of control negatively influenced amotivation while self-identity and external regulation positively influenced amotivation. The culmination of these findings indicates psychological blood donation barriers. These findings suggest one way to influence more people to become donors is to place greater focus on internal control through the positive emotional feelings they personally derive from the act of donating blood given that intrinsic motivation was shown to increase people's intention and reduce people's amotivation. For example, using testimonials from people who have needed blood can be an effective way to increase intrinsic motivation. A campaign suggesting that they are giving a newborn, a mother, a father or a sister another chance of life will be 
more effective than providing monetary incentives. Additionally, blood donation campaigns should have the inherent tendency of the individual to pursue interesting, fun and challenging tasks and to feel in control of that pursuit in an effort to foster growth. Donor's experience of donating blood, starting from registration, medical screening, blood collection and after blood donation, should not only be made pleasant and fun for the donor but also have a high level of personal involvement felt by the donor. Another suggestion is to connect the donors' experience through social media, a known interactive medium, highlighting how people feel good when doing the activities. However, this should be undertaken not through external regulation strategies suggesting people 'must' or 'have-to' donate blood, which may have limited impact on encouragement to donate blood through focusing on one's self-identity and extrinsic motivation thereby actually increasing people's amotivation but by highlighting the intrinsic value to the donor and letting them set the when and where for their donation. Giving monetary or cash equivalent incentives for blood donation may undermine the intrinsic motivation to donate blood especially toward regular donor. Recruiting donors by material incentive may promote the wrong culture of paid donation and undermine the important of saving patients' lives (Abolghasemi et al., 2010).

In conclusion, individuals who feel more in control of their own outcomes are more likely to be donating blood and engage in positive health behaviours. Hence, campaigns focusing on the positive feelings and suggesting donors to be in control of the timing and frequency of the blood donation (i.e. locus of control) may enhance donor recruitment and retention (Griffin et al., 2014; Hupfer et al., 2005; Martin et al., 2008; Sojka and Sojka, 2008). Finally, blood donation agencies (e.g. Redcross) can promote ease of blood donation and/or increase outlet availability to influence reluctant potential donors. 


\section{Limitations and Future Research}

Finally, limitations are inevitable in any research. Similar to other studies that draw widely on student populations (e.g. Burnet et. al., 2003), our sample was partly derived from a student population and moreover the convenience sample drawn in the present study was derived in one city in Australia. This may limit the generalizability of the findings. Future research should obtain data from other demographic categories (i.e. age, income, culture) in other cities in Australia. Some items selected from previous studies did not demonstrate sound reliability. These items had not previously been applied in the Australian blood donation context and the results indicate that further measure development may be required to ensure that reliable and valid measures are available for researchers and the practitioners community alike. Additionally, given the relationship between intentions to donate blood and actual blood donation behaviour have been shown to be weak (see Holdershaw et. al. 2011) additional research is recommended to examine the impact of amotivation on intention behaviour and self-reported or actual blood donation behaviour. One in thirty Australians currently donate blood and as such substantial samples need to be drawn in order to obtain a sufficient sample size of blood donors to permit structural equation modelling to be undertaken. The results of the current study can be used to inform experiments to understand how communications can be used to optimise intentions and subsequent donation behaviour while simultaneously reducing amotivation. For example, communications emphasising fun and pleasantness can be compared and contrasted to campaigns that emphasise community need (thereby inducing a feeling that people have to donate) to understand the optimal appeal. 


\section{References}

Abolghasemi, H., Hosseini-Divkalayi, N. S., \& Seighali, F. (2010), "Blood donor incentives: A step forward or backward", Asian journal of transfusion science, Vol. 4 No. 1, pp. 9-15.

Abramson, L. Y., Seligman, M. E. P., and Teasdale, J. D. (1978), "Learned helplessness in humans: Critique and reformulation", Journal of Abnormal Psychology, Vol. 87, pp. 49-74.

Ajzen, I. and Fishbein, M. (1980), Understanding Attitudes and Predicting Social Behaviour, Prentice Hall, Englewood Cliffs, NJ.Anderson, J. C., and Gerbing, D. W. (1988), "Structural equation modelling in practice: a review and recommended two-step approach", Psychological Bulletin, Vol. 103 No. 3, pp. 411-423.

Andreoni, J. (1989), "Giving with impure altruism: Applications to charity and ricardian equivalence”, Journal of Political Economy, Vol. 97 No. 6, pp. 1447-1458.

Andreoni, J. (1990), "Impure Altruism and Donations to Public Goods: A Theory of WarmGlow Giving", The Economic Journal, Vol. 100 No. 6, pp. 464-77.

Andreoni, J., and Bernheim, B.D. (2009), "Social image and the 50-50 norm: A theoretical and experimental analysis of audience effects", Econometrica, Vol. 77 No. 5, pp. 16071636.

Australian Red Cross Blood Service (2007), "Australian needs you”, available at: http://www.donateblood.com.au. (accessed 3 February 2015)

Australian Red Cross (2014), "Why should I give Blood?", available at: http://www.donateblood.com.au/faq\#faq 314. (accessed 3 February 2015).

Bagozzi, R. D. (1980), Casual Models in Marketing, New York: John Wiley and Associates.

Bandura, A. (1986), Social foundations of thought and action: A social cognitive theory, Englewood Cliffs, NJ: Prentice-Hall.

Barrett, P. (2007), "Structural Equation Modelling: Adjudging Model Fit", Personality and Individual Differences, Vol. 42 No. 5, pp. 815-24.

Benabou, R., and Tirole, J (2006), "Incentives and pro-social behaviour", American Economic Review, Vol. 96 No. 5, pp. 1652-1678.

Bollen, K. A. (1990), “Overall Fit in Covariance Structure Models: Two Types of Sample Size Effects", Psychological Bulletin, Vol. 107 No. 2 , pp. 256-59.

Brennan, L. M., Shaw, D. S., Dishion, T. J., \& Wilson, M. N. (2015), "The predictive utility of early childhood disruptive behaviors for school-age social functioning", Journal of abnormal child psychology, Vol. 43 No. 6, pp. 1187-1199.

Burnett, M., Keith, N., \& Pettijohn, C. (2003), “An empirical analysis of factors influencing student reactions to ethical advertising dilemmas: Educational experience, work experience, ethical philosophy, and demographics", Marketing Education Review, Vol. 13, pp. 33-46.

Burroughs, J. E., Chaplin, L. N., Pandelaere, M., Norton, M. I., Ordabayeva, N., Gunz, A., and Dinauer, L. (2013), "Using Motivation Theory to Develop a Transformative Consumer 
Research Agenda for Reducing Materialism in Society", Journal of Public Policy \& Marketing, Vol. 32 No. 1, pp. 18-31

Cerasoli, C. P., and Ford, M. (2014), "Intrinsic motivation and the mediating role of mastery goal orientation: A test of self-determination theory", Journal of Psychology, Vol. 148 No.3, pp. 267-286.

Cerasoli, C. P., Nicklin, J. M., and Fort, M.T. (2014), “ Intrinsic motivation and extrinsic incentives jointly predict performance: A 40-year meta-analysis", Psychological Bulletin, Vol 140 No. 4, pp. 980-1008.

Chen, J. Q., and Wang, L. (2007), Locus of control and the three components of commitment to change, Personality and Individual Differences, Vol/ 42, pp. 503-512.

Deci, E. L., and Ryan, R. M. (1980), The empirical exploration of intrinsic motivational processes", In L. Berkowitz (Ed.), Advances in experimental social psychology (Vol. 13, pp. 39-80). New York: Academic.

Deci, E. L., and Ryan, R. M. (1985), Intrinsic motivation and self-determination in human behaviour, New York: Plenum.

Deci, E. L., and Ryan, R. M. (1991), A motivational approach to self: Integration in personality", In R. Dienstbier (Ed.), Nebraska symposium on motivation: Vol. 38. Perspectives on motivation (pp. 237-288). Lincoln: University of Nebraska Press.

Deci, E. L., and Ryan, R. M. (2000). "The "What" and "Why" of Goal Pursuits: Human Needs and the Self-Determination of Behaviour", Psychology Inquiry, Vol. 11 No.4, pp. 227268.

Deci, E. L., and Ryan, R. M. (2008). Self-Determination Theory: A macro theory of human motivation, development, and health. Canadian Psychology, Vol. 49 No. 3, pp. 1823-185.

Diamantopoulos, A., and Siguaw, J. A. (2000), Introducing LISREL. London: Sage Publications.

Dillon, W. R., and Goldstein, M. (1984), Multivariate Analysis: Methods and Applications, New York: Wiley.

Ein-Gar, D., and Levontin, L. (2013), "Giving from a distance: Putting the charitable organisation at the center of the donation appeal", Journal of Consumer Psychology, Vol. 23 No. 2, pp. 197-211.

Eisenberg, N., Fabes, R. A., and Spinrad, T. L. (2006), Pro-social behaviour. in Handbook of Child Psychology: Vol. 3. Social, emotional, and personality development, $6^{\text {th }}$ Edn., W. Damonand R. M. Lerner (Seriesed) and N. Eisenberg, (Vol.ed), (NewYork, NY: Wiley), pp. 646-718.

Ellingsen, T., and Johannesson, M. (2008), "Pride and prejudice: The human side of incentive theory", American Economic Review, Vol. 98 No. 3, pp. 990-1008.

Ellingsen, T., and Johannesson. M. (2011), "Conspicuous generosity", Journal of Public Economics, Vol. 95 No.9-10, pp. 1131-1143. 
Etkin, J., and Ratkin, R. K. (2012), "The Dynamic Impact of Variety among Means on Motivation”, Journal of Consumer Research, Vol. 38 No. 6, pp. 1076-1092.

Fan, X., Thompson, B., and Wang, L. (1999), "Effects of Sample Size, Estimation Methods, and Model Specification on Structural Equation Modelling Fit Indexes," Structural Equation Modelling, Vol. 6 No.1, pp. 56-83.

Ferguson, E., Farrell, K., and Lawrence, C. (2008), "Blood donation is an act of benevolence rather than altruism", Health Psychology, Vol. 27 No. 3, pp. 327-332.

Fornell, C., \& Larcker, D. F. (1981), "Evaluating structural equation models with unobservable variables and measurement error", Journal of Marketing Research, Vol. 2, pp. $39-50$.

Güroğlu, B., Van den Bos, W. and Crone, E. A. (2014), "Sharing and giving across adolescence: an experimental study examining the development of pro-social behaviour", Frontiers in Psychology, Vol. 5, pp. 291-304.

Glynn, S. A., Kleinman, S. H., Schreiber, G. B., Zuck, T., Mc Combs, S., Bethel, J., and Williams, A. E. (2002), "Motivations to donate blood: demographic comparisons", Transfusion, Vol. 42 No. 2, pp. 216-225.

Griffin, D., \& O'Cass, A. (2010), “An exploration of personality and speed limit compliance", Journal of Nonprofit \& Public Sector Marketing, Vol. 22 No. 4, pp. 336-353.

Gregg, P., Grout, P. A., Ratcliffe, A., Smith, S., and Windmeijer, F. (2011), "How important is pro-social behaviour in the delivery of public services?", Journal of Public Economics, Vol. 95, pp. 758-766.

Grossman, Z. (2010), Self-signaling versus social signaling in giving. UCSB Working paper.

Guay, F., Vallerand, R. J., and Blanchard, C. (2000), "On the assessment of intrinsic and extrinsic motivation: The Situational Motivation Scale (SIMS)", Motivation and Emotion, Vol. 24 No. 3, pp. 175-513.

Hardre, P. L., and Reeve, J. (2003), “A motivational model of rural students' intentions to persist in, versus drop out of, high school”, Journal of Educational Psychology, Vol. 95, pp. 347-356.

Healy, K. (2000), "Embedded Altruism: Blood Collection Regimes and the European Union's Donor Population", American Journal of Sociology, Vol. 105 No. 6, pp. 1633-1657.

Hu, L., and Bentler, P. M. (1999), "Cutoff Criteria for Fit Indexes in Covariance Structure Analysis: Conventional Criteria Versus New Alternatives", Structural Equation Modelling, Vol. 6 No. 1, pp. 1-55.

Hupfer, M. E., Taylor, D. W., \& Letwin, J. A. (2005), “Understanding Canadian student motivations and beliefs about giving blood", Transfusion, Vol. 45 No. 2 , pp. 149-161.

Jameson, C. (1971), "Theory and nonsense of motivation research. European Journal of Marketing”, Vol. 5 No. 4, pp. 189-197.

Jung, J. Y. (2013), "Amotivation and Indecision in the Decision-Making Processes Associated with University Entry", Research in Higher Education, Vol. 54, pp. 115-136. 
Kashif, M., Sarifuddin, S., \& Hassan, A. (2015), "Charity donation: intentions and behaviour”, Marketing Intelligence \& Planning, Vol. 33 No. 1, pp. 90-102.

Kenny, D. A. (2014), Measuring model Fit, available at http://davidakenny.net/cm/fit.htm, (accessed 20 August 2014).

Kenny, D. A., and McCoach, D. B. (2003), "Effect of the Number of Variables on Measures of Fit in Structural Equation Modelling”, Structural Equation Modelling, Vol. 10 No.3, pp. 333-51.

Kindelberger, C., and Tsao R. (2014), "Staying Alone or Getting Attached: Development of the Motivations Toward Romantic Relationships During Adolescence", The Journal of Genetic Psychology, Vol. 175 No. 2, pp.147-162.

Kline, R. B. (2005), Principles and Practice of Structural Equation Modelling, 2nd ed. New York: The Guilford Press.

Lavigne, G. L., Hauw, N., Vallerand, R. J., Brunel, P., Blanchard, C., Cadoretta, I., and Angot, C. (2009), "On the dynamic relationships between contextual (or general) and situational (or state) motivation toward exercise and physical activity: A longitudinal test of the top-down and bottom-up hypotheses", International Journal of Sport and Exercise Psychology, Vol. 7, pp. 147-168.

Lemmens, K. P. H., Abraham, C., Ruiter, R. A. C., Veldhuizen, I. J. T., Dehing, C. J. G., Bos, A. E. R., and Schaalma, H. P. (2009), "Modelling antecedents of blood donation motivation among non-donors of varying age and education", British journal of psychology, Vol. 100 No.1, pp. 71-90.

Lindell, M. K., \& Whitney, D. J. (2001), "Accounting for common method variance in crosssectional research designs”, Journal of Applied Psychology, Vol. 86 No. 1, pp. 114.

MacCallum, R. C., Browne, R. W., and Sugawara, H. M. (1996), "Power Analysis and Determination of Sample Size for Covariance Structure Modelling", Psychological Methods, Vol. 1 No.2, pp. 130-49.

Markland, D., \& Tobin, V. (2004), “A modification to the behavioural regulation in exercise questionnaire to include an assessment of amotivation", Journal of Sport and Exercise Psychology, Vol. 26 No. 2, pp. 191-196.

Martin A. B., Hartman M., Whittle L., and Catlin A. (2014), "National Health Spending In 2012: Rate Of Health Spending Growth Remained Low For The Fourth Consecutive Year", Health Affairs, Vol. 33, No.1, pp. 67-77

Masser, B. M., White, K. M., Hyde, M. K., \& Terry, D. J. (2008), "The psychology of blood donation: current research and future directions", Transfusion medicine reviews, Vol. 22 No. 3 , pp. 215-233.

Masser, B. M., White, K. M., Hyde, M. K., Terry, D. J., \& Robinson, N. G. (2009), "Predicting blood donation intentions and behavior among Australian blood donors: testing an extended theory of planned behavior mode", .Transfusion, 49(2), 320-329.

Maslow, A. H. (1970), Motivation and Personality. New York: Harper and Row. 
Misje, A. H., Bosnes, V., Gåsdal, O., and Heier, H. E. (2005), "Motivation, recruitment and retention of voluntary non-remunerated blood donors: a survey-based questionnaire study", Vox sanguinis, Vol. 89 No. 4, pp. 236-244.

McClelland, D. C. (1987), Human Motivation. Cambridge, UK: Cambridge University Press.

Moore, R. J. (1991), "Promoting blood donation: a study of the social profile, attitudes, motivation and experience of donors", Transfusion Medicine, 1(4), 201-207.

Mottner, S., \& Ford, J. B. (2010), "International journal of nonprofit and voluntary sector marketing: special issue on marketing and religion", .International Journal of Nonprofit and Voluntary Sector Marketing, Vol. 15 No. 4, pp. 301-304.

Mowen, J. C. (2000), The 3M model of motivation and personality: Theory and empirical application to consumer behaviour, Boston, Kluwer Academic Publishers.

Ng, J. Y., Ntoumanis, N., Thøgersen-Ntoumani, C., Deci, E. L., Ryan, R. M., Duda, J. L., and Williams, G. C. (2012), "Self-Determination Theory Applied to Health Contexts: A MetaAnalysis", Perspectives on Psychological Science, Vol. 7 No. 4, pp. 325-340.

Ng, S., (2010), "Cultural Orientation and Brand Dilution: Impact of Motivation Level and Extension Typicality”, Journal of Marketing Research, XLVII (February), pp. 186-198.

Niza, C., Tung, B., \& Marteau, T. M. (2013), "Incentivizing blood donation: Systematic review and meta-analysis to test Titmuss' hypotheses", Health Psychology, Vol. 32 No. 9, pp. 941.

Nunally, J.C. (1978), Psychometric Theory, McGraw-Hill, New York, NY.

Nunnally, J., and Bernstein, I. H. (1994). Psychometric Theory, $3^{\text {rd }}$ ed. New York, NY: McGraw Hill.

O'Cass, A., \& Griffin, D. (2015), "Eliciting positive social change: marketing's capacity to drive prosocial behaviours", Marketing Intelligence \& Planning, Vol. 33 No. 5, pp. 826-843.

Oakley, A., \& Ashton, J. (1997). The gift relationship: from human blood to social policy. London School of Economics and Political Science,(LSE).

Payne, J. W., Bettman, J. R., and Johnson, E. J. (1992), "Behavioural decision making: A constructive processing perspective", Annual Review of Psychology, Vol. 43, pp. 87-131.

Poch, R., and Martin, B. (2014), "Effects of intrinsic and extrinsic motivation on usergenerated content", Journal of Strategic Marketing, DOI: 10.1080/0965254X.2014.926966.

Ratelle, C. F., Guay, F., Vallerand, R. J., Larose, S., and Sene'cal, C. (2007), “Autonomous, controlled, and amotivated types of academic motivation: A person-oriented analysis", Journal of Educational Psychology, Vol. 99 No. 4, pp. 734-746.

Red Cross (2014), "Facts about the blood supply", Available at: http://www.redcrossblood.org/learn-about-blood/blood-facts-and-statistics. (accessed: 3 February 2015).

Richins, M. L. (1994), "Special Possessions and the Expression of Material Values", Journal of Consumer Research, Vol. 21 No. 12, pp. 522-33. 
Rise, J., Sheeran, P., and Hukkelburg, S. (2010), "The role of self-identity in the theory of planned behaviour: A meta-analysis", Journal of Applied Psychology, Vol. 40 No.5, pp. $1085-1105$.

Robbins, S. B., Lauver, K., Huy, L., Davis, D., Langley, R., and Carlstrom, A. (2004), “Do psychosocial and study skill factors predict college outcomes? A meta-analysis", Psychological Bulletin, Vol. 130, pp. 261-288.

Rotter, J. B. (1966), "Generalized expectancies for internal versus external control of reinforcement”, Psychological Monographs, Vol. 80, pp. 1-28.

Ryan, R. M., Connell, J. P. and Deci, E. L. (1985), Amotivational analysis of selfdetermination and self-regulation in education. In C. Ames and R.E. Ames (Eds.), Research on motivation in education: The classroom milieu (pp. 13-51). New York: Academic.

Ryan, R. M. (1995), "Psychological needs and the facilitation of integrative processes", Journal of Personality, Vol. 63, pp. 397-427.

Ryan, R. M., Kuhl, J., and Deci, E. L. (1997), "Nature and autonomy: Organizational view of social and neurobiological aspects of self-regulation in behavior and development", Development and Psychopathology, Vol. 9, pp. 701-728.

Ryan, R. M., and Deci, E. L. (2000), "Self-determination theory and the facilitation of intrinsic motivation, social development and well-being", American Psychologist, Vol. 55 No.1, pp. 68-78.

Ryon, H. S., and Gleason, M. E. J. (2014), "The Role of Locus of Control in Daily Life", Personality and Social Psychology Bulletin, Vol. 40 No. 1, pp. 121-131

Schwartz, S. H. (2006), "Les valeurs de base de la personne: Théorie, mesures et applications [Basic human values: Theory, measurement, and applications]", Revue Française de Sociologie, Vol. 47, pp. 249-288.

Seligman, M. E. P. (1975), Helplessness, San Francisco: Freeman.

Simons, J., Dewitte, S., and Lens, W. (2004), "The role of different types of instrumentality in motivation, study strategies, and performance: Know why you learn, so you'll know what you learn!", British Journal of Educational Psychology, Vol. 74, pp. 343-360.

Smith, J. R., and McSweeney, A. (2007), "Charitable Giving: The Effectiveness of a Revised Theory of Planned Behaviour Model in Predicting Donating Intentions and Behaviour", Journal of Community \& Applied Social Psychology, Vol. 17, pp. 363-386.

Sojka, B. N., \& Sojka, P. (2008), “The blood donation experience: self-reported motives and obstacles for donating blood", Vox sanguinis, Vol. 94 No. 1, pp. 56-63.

Spector, P. E. (1988), "Development of the Work Locus of Control Scale", Journal of Occupational Psychology, Vol. 61,pp. 335-340.

Steele, W.R., Schreiber, G.B., Guiltinan, A., Nass, C., Glynn, S.A., Wright, D.J., Kessler, D., Schlumpf, K.S., Tu, Y., Smith, J.W. and Garratty, G. (2008), "The role of altruistic behavior, empathetic concern, and social responsibility motivation in blood donation behaviour", Transfusion, 48(1), 43-54. 
Stets, J. E., and Burke, P. J. (2000), "Identity theory and social identity theory", Social Psychology Quarterly, Vol. 63, pp. 224-237.

Stets, J. E., and Burke, P. J. (2003), A sociological approach to self and identity. In M. R. Leary and J. P. Tangney (Eds.), Handbook of self and identity (pp. 128-152). New York: Guilford.

Titmuss, R. (1971), The gift relationship: From human blood to social policy, New York, Vintage, 1971.

Thoits, P.A. (1992), "Identity structures and psychological well-being: Gender and marital status comparison”, Social Psychology Quarterly, Vol. 55, pp. 236-256.

Thoits, P. A. (2013), Self, identity, stress, and mental health, In Handbook of the sociology of mental health (pp. 357-377). Springer Netherlands.

Thoits, P. A., and Virshup, L. K. (1997), Me's and we's: Forms and functions of social identity. In R. Ashmore \& L. Jussim (Eds.), Self and identity: Fundamental issues (Vol. 1, pp. 106-133). New York: Oxford University Press.

Tonin, M., and Vlassopoulos, M. (2014), "An experimental investigation of intrinsic motivations for giving”, Theory and Decision Making, Vol. 76, pp. 47-67.

Vallerand, R. J., and Bissonnette, R. (1992), "Intrinsic, extrinsic, and amotivational styles as predictors of behaviour: A prospective study", Journal of Personality, Vol. 60 No. 3, pp. 599-620.

Vallerand, R. J., Blanchard, C. M., Mageau, G. A., Koestner, R., Ratelle, C., L'eonard, M., and Marsolais, J. (2003), "Les passions de 1'^ame: On obsessive and harmonious passion", Journal of Personality and Social Psychology, Vol. 85, pp. 756-767.

Werts, C. E., Linn, R. L., and Joreskog. K. G. (1974), "Interclass reliability estimates: Testing structural assumptions", Educational and Psychological Measurement, Vol. 34, pp. 25-33.

World Health Organization. (2010). World health statistics 2010. Available at: http://www.who.int/whosis/whostat/EN WHS10 Full.pdf (accessed 10 February 2015).

Yuan, K. (2005), "Fit Indices Versus Test Statistics", Multivariate Behavioural Research, Vol. 40 No. 1, pp. 115-48.

Zhang Y. and Szu-Chi H. (2010), "How Endowed versus Earned Progress Affects Consumer Goal Commitment and Motivation”, Journal of Consumer Research, Vol. 37, No. 12, pp. 641-654.

Zito, E., Alfieri, S., Marconi, M., Saturni, V., \& Cremonesi, G. (2012), “Adolescents and blood donation: motivations, hurdles and possible recruitment strategies", Blood Transfusion, Vol. 10 No. 1, 45. 


\section{Appendix}

Figure 1. Path diagram

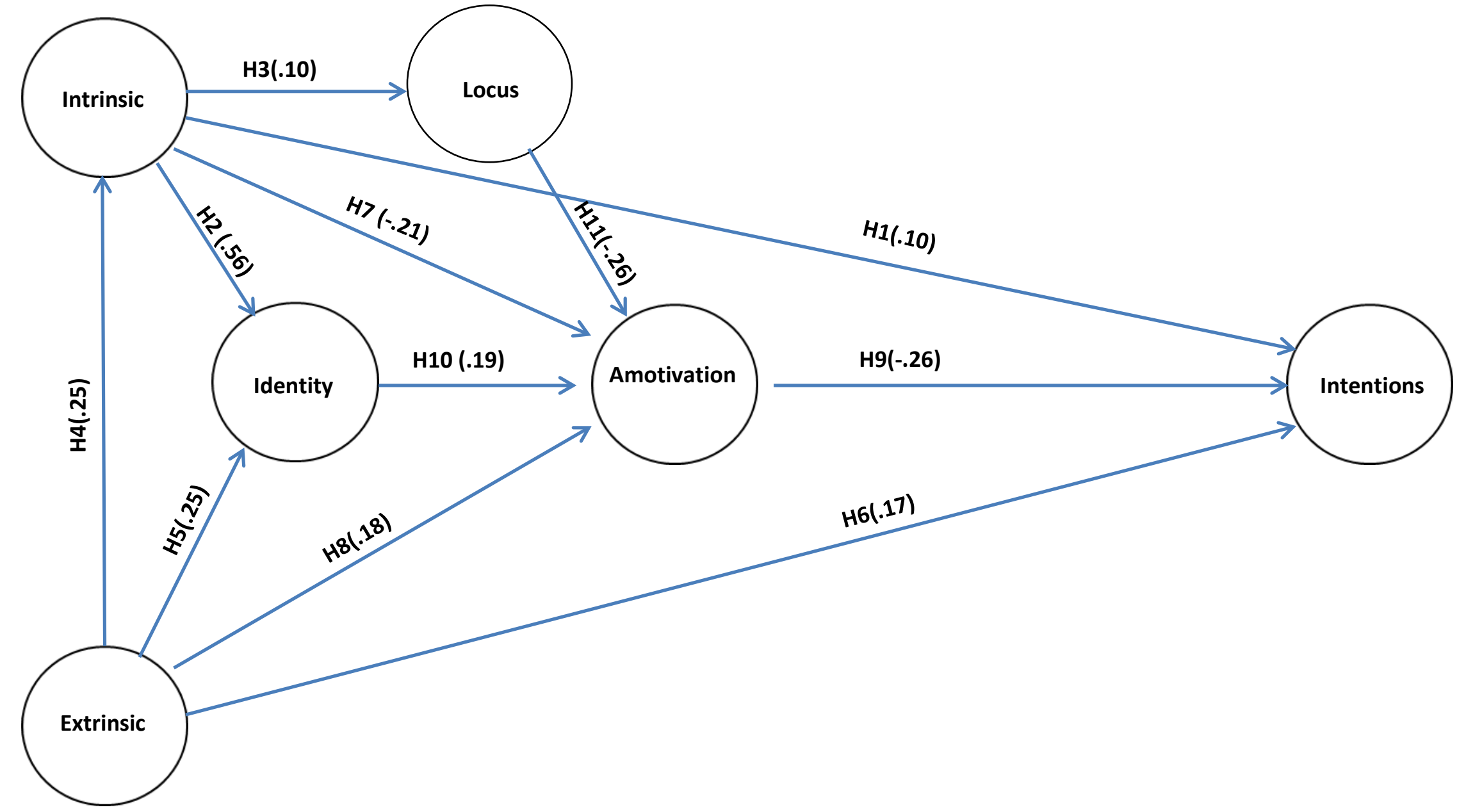

Note: $\rightarrow$ = significant; - -> = not significant 
Table 1. Reliability and Construct Average Variance Extracted

\begin{tabular}{|c|c|c|c|c|c|c|}
\hline Construct & Item & Loading & Initial $\alpha$ & Final $\alpha$ & AVE & rho \\
\hline \multirow{6}{*}{$\begin{array}{l}\text { Locus of } \\
\text { control }\end{array}$} & - $\quad$ Life is what you make of it. & .69 & \multirow[t]{6}{*}{.61} & \multirow[t]{6}{*}{.69} & \multirow[t]{6}{*}{.57} & \multirow[t]{6}{*}{.72} \\
\hline & - If you are unhappy with life you should do something about it. & .81 & & & & \\
\hline & Item removed: & & & & & \\
\hline & - If you know what you want out of life, you will find it. & .49 & & & & \\
\hline & - $\quad$ Life is a matter of good fortune & .14 & & & & \\
\hline & - Getting the life you desire is mostly a matter of luck & .23 & & & & \\
\hline \multirow{5}{*}{$\begin{array}{l}\text { Intrinsic } \\
\text { motivation }\end{array}$} & - $\quad$ the activity is interesting & .77 & \multirow[t]{5}{*}{.82} & \multirow[t]{5}{*}{.82} & \multirow[t]{5}{*}{.66} & \multirow[t]{5}{*}{.85} \\
\hline & - $\quad$ the activity is pleasant & .86 & & & & \\
\hline & - the activity is fun & .80 & & & & \\
\hline & Item removed: & & & & & \\
\hline & - $\quad$ because I feel good when doing the activity & .50 & & & & \\
\hline \multirow[t]{5}{*}{ Self-Identity } & - $\quad$ for my own good & .76 & \multirow[t]{5}{*}{.68} & \multirow[t]{5}{*}{.72} & \multirow[t]{5}{*}{.53} & \multirow[t]{5}{*}{.77} \\
\hline & - $\quad$ this activity is good for me & .81 & & & & \\
\hline & - this activity is important for me & .59 & & & & \\
\hline & Item removed: & & & & & \\
\hline & - $\quad$ my personal decision & .30 & & & & \\
\hline \multirow{4}{*}{$\begin{array}{l}\text { Extrinsic } \\
\text { motivation }\end{array}$} & - I am supposed to do it & .80 & \multirow[t]{4}{*}{.83} & \multirow[t]{4}{*}{.83} & \multirow[t]{4}{*}{.64} & \multirow[t]{4}{*}{.84} \\
\hline & - $\quad$ something that I have to do & .89 & & & & \\
\hline & - $\quad$ because I feel that I have to do it & .69 & & & & \\
\hline & - $\quad$ because I don't have any choice & .56 & & & & \\
\hline \multirow[t]{4}{*}{ Amotivation } & - I don't see any good reasons & .79 & \multirow[t]{4}{*}{.88} & \multirow[t]{4}{*}{.88} & \multirow[t]{4}{*}{.64} & \multirow[t]{4}{*}{.88} \\
\hline & - $\quad$ not sure if it is worth it & .84 & & & & \\
\hline & - don't see what this activity brings me & .82 & & & & \\
\hline & - $\quad$ not sure it is a good thing to pursue it & .73 & & & & \\
\hline \multirow[t]{3}{*}{ Intentions } & - I would like to donate & .97 & \multirow[t]{3}{*}{.89} & \multirow[t]{3}{*}{.89} & \multirow[t]{3}{*}{.75} & \multirow[t]{3}{*}{.90} \\
\hline & - $\quad$ I intend to donate & .78 & & & & \\
\hline & - $\quad$ I will donate & .84 & & & & \\
\hline
\end{tabular}

Note: 1 . Fit indices (Measurement Model): $\mathrm{CFI}=.98 ; \mathrm{RMSEA}=.03 ; \chi^{2}=198.200 ; \mathrm{RMR}=.06$ 
Table 2. SEM Regression Weights

\begin{tabular}{|llll|}
\hline Hypothesis & Parameter & Sig & Supported \\
\hline 1 & Intrinsic $\rightarrow$ Intentions & .03 & Yes \\
\hline 2 & Intrinsic $\rightarrow$ Identity & .00 & Yes \\
\hline 3 & Intrinsic $\rightarrow$ Locus & .05 & Yes \\
\hline 4 & Extrinsic $\rightarrow$ Intrinsic & .00 & Yes \\
\hline 5 & Extrinsic $\rightarrow$ Identity & .00 & Yes \\
\hline 6 & Extrinsic $\rightarrow$ Intentions & .00 & Yes \\
\hline 7 & Intrinsic $\rightarrow$ Amotivation & .00 & Yes \\
\hline 8 & Extrinsic $\rightarrow$ Amotivation & .00 & Yes \\
\hline 9 & Amotivation $\rightarrow$ Intentions & .00 & Yes \\
\hline 10 & Identity $\rightarrow$ Amotivation & .01 & No \\
\hline 11 & Locus $\rightarrow$ Amotivation & .00 & Yes \\
\hline
\end{tabular}

